\title{
Online Teaching in Ayurveda Medical Education during COVID 19 Pandemic - A Descriptive Survey Study
}

\author{
Research Article
}

\section{Unnikrishnan VV1, Ansary PY2*, Shalu Varghese1}

\section{Dean [Academic], Kerala University of Health Sciences, Thrissur, Kerala.}

2. Dean [Ayurveda], Kerala University of Health Sciences, Thrissur, Kerala.

3. Research Assistant, Academic Staff College, Kerala University of Health Sciences, Thrissur, Kerala, India.

\begin{abstract}
The impact of COVID 19 has disrupted all domains of human existence and educational institutions around the world. The national lockdown caused major interruption in students learning, both theory and practice; disruptions in internal assessments and the postponement of qualifying university examinations in health science education institutions. In order to assess the magnitude and the severity of the impact of the catastrophe on the health science education sector in the state, the Kerala University of Health Sciences (KUHS), Thrissur, Kerala conducted online surveys among the stake holders during April-May 2020. Objectives: To assess the perceptions of Ayurveda faculty members on online teaching during COVID 19 pandemic on the health science education institutions in Kerala. Materials and Methods: This descriptive online survey study was targeted the Faculty members from 17 Ayurveda colleges affiliated to Kerala University of Health Sciences. A total of 314 valid responses were collected regarding Ayurveda faculty members perceptions of online teaching during COVID 19 pandemic prevention and control strategy in Kerala using semi structured questionnaire in Google form. The responses were analyzed using descriptive statistics. Results: The results of the survey of 314 Ayurveda faculty members indicate that the majority of these teachers support online teaching strategies in order to bridge the learning gap and epidemic prevention and control initiative. Conclusions: Facing an unprecedented situation, the problems and challenges encountered by Ayurveda faculty in switching to and providing online learning will serve as a reference for other countries as they explore and implement online teaching programs.
\end{abstract}

Key Words: COVID 19, Pandemic, Ayurveda, Perception, Online Teaching, Online Learning.

\section{Introduction}

The COVID-19 has resulted in schools and colleges shut all across the world. Globally, over 1.2 billion children are out of the classroom. As a result, education has changed dramatically, with the distinctive rise of e-learning, whereby teaching is undertaken remotely and on digital platforms.(1) COVID-19 is causing unforeseen damages in the world. India is not spared, but we are bravely facing it with a long drawn out lock-down. Academics is one of the key areas affected. Students are one of the most affected groups in the present scenario.(2)

The sudden outbreak of the COVID-19 resulted in the unexpected long term closure of Colleges and interrupting teaching plans. In this juncture Kerala University of Health Science recommended all affiliated Ayurveda colleges to adopt online teaching strategies in order to bridge the learning gap.(3) Electronic learning

\section{* Corresponding Author:}

\section{Ansary PY}

Dean [Ayurveda],

Kerala University of Health Sciences,

Thrissur,

Kerala- 695006, India

Email Id: dransarypy@gmail.com (e-learning) has gained reasonable acceptance from educational institutions at all levels. With the advent of information technology and its growing use in education sector, a transformation is seen in traditional and conventional teaching methods that are used in schools. E-learning poses a challenge to both teachers and students over technology and access, and keeping everyone with computers and smart phone screens.(4)

The COVID-19 crisis has resulted in the proliferation of different online teaching learning platforms. Situation necessitates the faculty to learn about the technology and etiquette of online teaching. Many are inexperienced when it comes to using the new technologies and interfaces.(1) Despite the potential pitfalls and difficulty, the vast majority of Ayurveda faculty members were ready to take online classes. In this scenario, the KUHS decided to make a real-time assessment of the situation to arrive at specific, targeted conclusions.

\section{Materials and Methods}

A Descriptive online survey was conducted from April 25 to April 28, 2020, the survey targeted faculty members from 17 Ayurveda colleges affiliated to Kerala University of Health Sciences on a random basis. A total of 314 valid responses were collected regarding Ayurveda Faculty Members Perceptions of Online Teaching during COVID 19 pandemic in Kerala. 
The Semi structured questionnaire in Google form was used to collect data. The responses were analyzed online using descriptive statistics.(5)

\section{Result}

Among Ayurveda Faculty Members of affiliated institutions under KUHS who participated in the online survey $45.22 \%$ were Males and $54.78 \%$ were Females (Fig-1). Of them 3.5\% were Lecturers, 33.12\% faculty participated in the survey were Assistant Professors, $38.22 \%$ were Associate Professors and 25.16\% were Professors (Fig-2). Among Ayurveda faculty members $67.83 \%$ of the faculty members belong to private sector, $12.73 \%$ government and $19.42 \%$ were from aided Institution.

Percentage distribution of Ayurveda faculty members based on gender

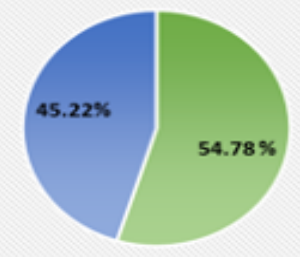

Male Female

Figure 1: Percentage distribution of Ayurveda faculty members based on gender

Percentage distribution of Ayurveda faculty members based on designation

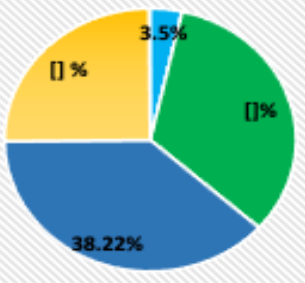

- Lecturer

- Assistant Prolesser

- Associate Professor

- Prolessor

Figure 2: Percentage distribution of Ayurveda faculty members based on designation

\section{i) Perception of Ayurveda Faculty members on effect of lockdown}

The Ayurveda Faculty members were asked in what all ways have the Lockdown affected the academic environment. Among them 88.2\% Faculty members opinioned that lockdown affected examinations most. The following are excerpts from the transcripts:

- "Examination is greatly affected by lockdown, both internal and University”. (Ayur1)

- "The conventional classes, internal assessment examinations, practical sessions, etc. were affected badly". (Ayur 2)

Among them, $74.6 \%$ reported that classes were affected, $70 \%$ responded as it resulted in loss of one-to-one interaction with students, colleagues and at the least $14.6 \%$ reported extracurricular activities became affected. The following are excerpts from the transcripts:
- "We used to have small group learning classes and we used to have daily learning program early in the morning called' swadhyayam'. Both got stopped during lockdown". (ayur3)

- Personal contact with student is necessary for a Professional Course. Now we are unable to identify the weak students and don't know whether malpractices are occurring during examination (Ayur4)

- "We could not give personal attention to weak students. Classes are conducted online via zoom, so one- to- one interaction with students is less than that of a traditional classroom". (Ayur5)

- Other area affected was clinical posting / practical experience, $11.41 \%$ mentioned their opinion regarding the loss of practical hours.

- "Clinical practices, practical experience and case study etc. are affected by lockdown”. (Ayur6)

ii) Ayurveda Faculty members view on effectiveness of online teaching in regular learning

As many as $50.32 \%$ Faculty members found that using existing online education platforms are effective in regular learning and rated three points; $28.98 \%$ of them rated four points and $9.88 \%$ rated five points. (Fig-3).

\section{Effectiveness of online teaching learning activity based on the opinion given by Ayurveda Faculty members}

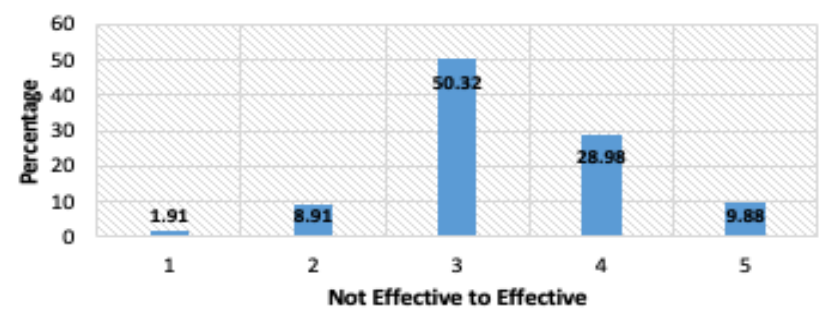

Figure 3: Effectiveness of online teaching learning activity based on the opinion given by Ayurveda Faculty members

Faculty members were asked whether online class is effective in bridging the learning gap, $44.58 \%$ faculty rated three for effectiveness of online class in bridging the gap, $31.84 \%$ rated four points and $6.07 \%$ rated five points (Fig-4).

Percentage distribution of faculty based on opinion regarding whether online teaching is effective in bridging the learning gap

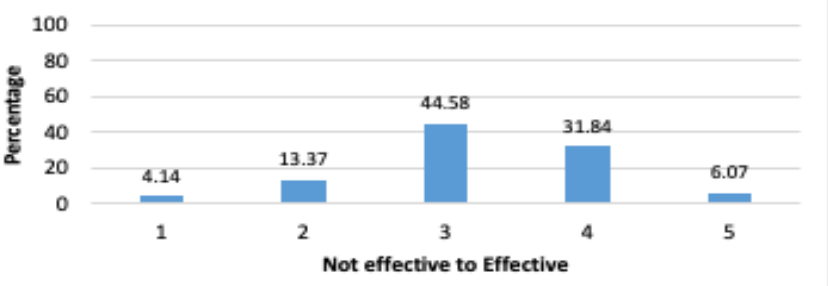

Figure 4: Percentage distribution of faculty based on opinion regarding whether online teaching is effective in bridging the learning gap 
While discussing with Faculty members, regarding the factors that affect the acceptability and compliance of online teaching program by the students, $76.4 \%$ of faculty members opined that students accept online teaching program since it is available in their home environment itself, $72 \%$ accepted because online teaching program gives space to learn in relaxed manner, $62.4 \%$ accepted online teaching program due to freedom in the time schedule, $57.7 \%$ due to less pressure and $36.9 \%$ accepted due to creativity in learning.

Other factors affecting the acceptance and compliance of online teaching includes; user friendliness, recorded materials might be useful for revision, assessment becomes liberal, stress free learning, faculty members are using novel techniques and methods to get their ideas across, independent in studies, students are more acquaint to digital world and online class improves imagination.

\section{iii) The perceived advantages of online teaching}

Most of them $(50.32 \%)$ found that online classes are helpful for Ayurveda students as well as faculty members. They are benefited with same purpose of learning that they initially were before the lock down started. This is helping the faculty members to communicate with their students and share knowledge. (6) Due to the pace at which the web classes are functioning the scholars are ready to dedicate a while learning albeit they're actually not getting to the place at which it is taught. Some advantages are listed below;

- More Teaching Opportunities/advanced teaching technology

- Better administration and management

- Finishes the portions without delay

- Time and Location Flexibility

- Convenient time and not time bound

- Timely assessment, feedback increases student learning

- Keeps updated without losing touch with the topics

- Easy to find problematic and distracted student

- Stress free

- More engagement between student and the teacher

- Can note the student individually in online video call session by maintaining eye contact

\section{iv) The perceived difficulties of online teaching}

Comparing face-to-face learning with online learning brings forth significant deficiencies in the online mode such as lack of human connect, absence of opportunities of collaborative learning, teacher supervision and the most glaring being lack of opportunities for hands-on learning in practical oriented subjects.(7) Some of the difficulties noted in the survey are listed below;

- Difficult to maintain eye contact and eye straining

- Difficult to conduct group discussions

- Student can opt whether to respond or not

- Feedback and assessment may not be genuine

- Lack of internet connectivity and limitation of data

- Lack of facility with the student

- Cannot assure students are attending

- Difficult to take attendance
- Affect face to face interaction, Can't see the real time facial expressions and body language of students

- Learning vary according to the age of the learner

- No real satisfaction for faculty members as well as for students

- Lacks concentration

- Decrease interest as time progress

- Cannot carry out practical sessions

- Safety consent on online platform

- Level of understanding cannot be assessed

- Difficult for faculty members and students who are technologically weak

However, it has been observed that the things taught through online mode have a lot many challenges for the educator as well as the learner.(8)

\section{v) Online mode of teaching}

This section explores the platforms used by the surveyed Ayurveda faculty. Survey results indicate that most of the faculty used WhatsApp (76.1\%) for online sharing of video, reading materials etc., $41.4 \%$ used Zoom platform for taking classes and $38.7 \%$ used Google classroom. Other digital platforms used were; Gmail, PPT Sharing, Canvas instructor, Video Recording, Skype, Google Meet, Google teams, Google Classroom, Telegram, Go to Webinar, Go to Meeting, Voov, Telephone Group Call, ERP Software, Screenshot, Google Hangout, JITSIMEET, Google Form, Edmodo, Blue jeans, Survey Monkey and Survey Heart, Join me, Class Maker Website, MS Teams, Google Duo, Institutional software, Face book closed group/ Live, Quizziz.com, Saynamste, Impartus platform, Office 365, Campus Suite, Google drive sharing, Kinemaster app.

\section{vi) Recording Attendance}

Mostly (64.8\%) attendance was recorded by noting reporting and feedback from the students, $54.1 \%$ given attendance based on the submission of assignments, $34.1 \%$ used digital application to record attendance and $21 \%$ by physically looking at the screen.

In order to ensure student interaction during online session $65.6 \%$ used assignment, $63.6 \%$ used asking question, $63.1 \%$ used feedback and $47.3 \%$ used online tests. Other methods adopted to ensure student interaction includes; conducting test papers under the supervision of parents, assignments are given beforehand, using Survey Monkey App to obtain feedback and comments, encouraging questions via chat option, random checking of notes, asked to write a summary of lesson and send back to the teacher, doubt clearing session and telephonic feedback.

\section{vii) Assessment Methods}

Faculty members were asked about the assessment methods utilized during online classes, $52.4 \%$ used online assessment after several classes as assessment strategy, $50.4 \%$ done assessment immediately after the class and $32.7 \%$ planned to do assessment after lockdown gets over. The following excerpt from the transcripts support these findings: 
- "Even though online line classes are going on assessment is difficult" (Ayur8).

- "Students are not getting conducive environment to study and it's difficult to teach first year students purely online" (Ayur9)

\section{viii) Faculty member's expectations}

The questionnaire also explored faculty member's willingness to incorporate and normalize online teaching in their daily teaching practice once the epidemic is over. In this respect, $27.07 \%$ showed willingness and most of them $(72.93 \%)$ were extremely unwilling to do so (Fig- 5). Most of the respondents believed that the online teaching program was conducive to improving the information literacy of both faculty members and students. The following excerpt from the transcripts support these findings:

- "Learning Ayurveda involves the participation of all senses and hence in online platforms the learning would be imperfect". (Ayur10)

\section{Percentage distribution of Ayurveda Faculty based on willingness for continuation of online classes even after lockdown}

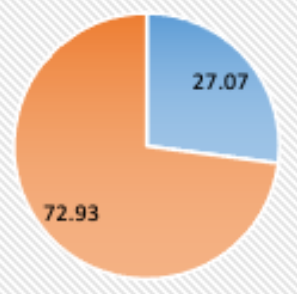

Figure 5: Percentage distribution of Ayurveda Faculty based on willingness for continuation of online classes even after lockdown

\section{Discussion}

The campuses have been shut down, but most of the faculty members were working from home, preparing effective study material for their students so that there isn't any hindrance to the teaching-learning process. Faculty members had to make them available for students at all times of the day in order to reduce their hardships and disruption being caused to the students across the country at this point in time due to the COVID 19 pandemic.

The present situation necessitates the stakeholders to move into online teaching; a less tried and tested modality of Teaching - Learning Method, in an unprecedented scale. Student assessments might need to go online in varying degrees, which might further the uncertainty for everyone involved. The challenges of online learning will be managed sooner. (9)

The results of the survey of 314 Ayurveda faculty indicate that the majority of faculty members support online teaching strategies in order to bridge the learning gap and epidemic prevention and control initiative. However, certain difficulties remain. Facing an unprecedented situation, the problems and challenges encountered by Ayurveda faculty in switching to and providing online learning will serve as a reference for other countries as they explore and implement online teaching programs.

The present study findings are also consistent with the finding of a survey of 15,438 Chinese teachers in East China Normal University indicate that 52.12\% of the teachers "strongly support" the initiative, $34.75 \%$ "somewhat support" the initiative, $11.02 \%$ are "somewhat opposed," and $2.11 \%$ are "strongly opposed". Although online teaching programs were hastily implemented and fairly makeshift, the majority of teachers appear willing to work alongside their students and school administrators in ensuring a systematic online learning environment, including investing the necessary effort in training and overcoming difficulties. With the support and organization of various departments, teachers were provided with immediate training in online teaching and platforms.(10)

Technological advances are here to stay, and crises such as the current pandemic only come to highlight the digital deficit not just in terms of supporting technology, or student skills, but also and perhaps most importantly as regards teacher perceptions, attitudes, and actual preparedness. Consequently, teacher educators need to prepare to understand that online teaching requires its own set of skills, tools, and teaching practices.(11)

\section{Conclusions}

- We need to standardize the online Teaching Learning \& Assessment systems.

- Appropriate low bandwidth platforms have to be found out

- Good resource materials have to be prepared

- Faculty members have to be constantly motivated to evolve.

- Sanctity of Online Examinations has to be reiterated and validated.

\section{Sources of funding}

No financial support received for this study.

\section{Conflict of Interest}

Authors declare that they need no conflict of interests.

\section{Ethical Issues}

An online consent was taken from all participants during the study.

\section{Acknowledgments}

The authors would like to thank all those how helped to complete this research.

\section{Reference}

1. Kurien J. Online teaching pandemic in the time of Covid crisis: Where is it heading? [Internet]. 2020 [cited 2020Ju18]. Available from: https:// www.onmanorama.com/news/columns/straight-talk/ 
2020/06/15/online-teaching-pandemic-covidcoronavirus-crisis.html

2. Impact of the COVID-19 pandemic on education [Internet]. Wikipedia. Wikimedia Foundation; 2020 [cited 2020Ju13]. Available from: https:// e n. w i k i p e d i a o r g / w i k i / Impact_of_the_COVID-19_pandemic_on_educatio $\mathrm{n}$

3. Kerala University of Health Science. [cited 2020 Jun 26]. Available from: http://www.kuhs.ac.in/

4. (IJACSA) International Journal of Advanced Computer Science and Applications. Vol. 7, No. 9, 2016.

5. Descriptive \&amp; Inferential Statistics: Definition, Differences \&amp; Examples - Video \&amp; Lesson Transcript [Internet]. Study.com. Study.com; [cited 2020Jul3]. Available from: https://study.com/ academy/lesson/descriptive-and-inferentialstatistics.html

6. Distance education [Internet]. 2020 [cited 2020Jul3]. Available from: https://en.wikipedia.org/ wiki/Distance_education

7. (PDF) A Newcomer's Lens: A Look at K-12 Online and Blended Learning in the Journal of Online Learning Research [Internet]. Research Gate. [cited $2020 \mathrm{Ju} 13$ ]. Available from: https:// www.researchgate.net/publication/
336014931 A Newcomer's Lens A Look at K-1 2_Online_and_Blended_Learning_in_the_Journal of_Online_Learning_Research

8. Howell S $\bar{L}$, Williams P B, Lindsay N K. Thirty-two trends affecting distance education: An informed foundation for strategic planning. Online Journal of Distance Learning Administration. 6: 1-18, 2003 dated 06-07-2020 time 12:05 ISM

9. Remote learning recommendations - Illinois State Board of ... [Internet]. [cited 2020Jul3]. Available from: https://www.isbe.net/Documents/RLRecommendations-3-27-20.pdf

10. Yang X. Teachers' Perceptions of Large-Scale Online Teaching as an Epidemic Prevention and Control Strategy in China. ECNU Review of Education. 2020 May 7:2096531120922244 dated 03-07-2020 time 11:20 ISM

11. Chandan Kumar Karmakar, Mufassil Wahid CM. Recommendations for Bangladesh towards elearning readiness. Department of Computer Science and Engineering. Shah Jalal University of Science and Technology, Sylhet, Bangladesh. 2000:97-102. Available from:http:// citeseerx.ist.psu.edu/viewdoc/download? doi=10.1.1.514.5556\&rep $=$ rep1\&type $=$ pdf dated 03-07-2020 time 14:00 ISM. 